Disponível em

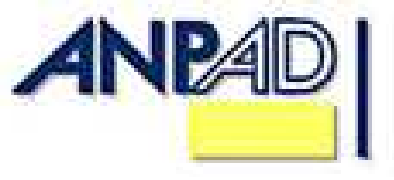
http://www.anpad.org.br/rac

RAC, Rio de Janeiro, v. 16, n. 5, art. 3, pp. 684-704, Set./Out. 2012

(cc) EY-NG

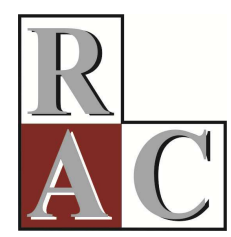

\title{
A Etnometodologia enquanto Caminho Teórico-metodológico para Investigação da Aprendizagem nas Organizações
}

The Ethnomethodology as a Theoretical-methodological Way for Research in Organizational Learning from the Perspective of Practice Based Studies

Marcelo de Souza Bispo * E-mail: marcelodesouzabispo@gmail.com Universidade Federal da Paraíba - UFPB João Pessoa, PB, Brasil.

Arilda Schmidt Godoy E-mail: arilda-godoy@uol.com.br Universidade Presbiteriana Mackenzie

São Paulo, SP, Brasil. 


\title{
Resumo
}

Pensar as organizações enquanto campos simbólicos nos quais as pessoas convivem em constante interação mediada pela linguagem e, assim, constroem significado e sentido para suas atividades cotidianas, faz delas um espaço de aprendizagem e geração de conhecimento, envolvendo negociação e troca contínuas. As demandas sobre as organizações por inovação e mudança em razão do ambiente competitivo em que vivem sugerem novas formas de pensar o que é aprender e conhecer, que parece ir além do que está disponível nos meios formais de aprendizagem em que o conhecimento tácito e a aprendizagem coletiva resultando das interações sociais cotidianas ganham espaço. A partir dessa perspectiva, este ensaio tem como objetivo apresentar e analisar a possibilidade de investigação dos processos de aprendizagem nas organizações a partir do conceito de prática e à luz da etnometodologia, examinando como se articulam tais ideias e em que medida elas trazem novas maneiras de ver e compreender esse fenômeno. Sob as lentes da etnometodologia garfinkeliana, o texto traz um olhar diferenciado para a compreensão da aprendizagem organizacional a partir do conceito de prática (Gherardi, 2006). Como principais reflexões, o ensaio destaca que enxergar a aprendizagem organizacional sob os pressupostos da etnometodologia implica, necessariamente, pensar esse fenômeno a partir das práticas cotidianas das organizações e traz também a discussão sobre a demanda por uma melhor sistematização da etnometodologia como possibilidade de investigação empírica para as pesquisas em Administração.

Palavras-chave: etnometodologia; estudos baseados em prática; aprendizagem organizacional.

\begin{abstract}
Thinking of organizations as symbolic fields where people live in constant interaction mediated by language, thus constructing meaning and sense for their daily activities, makes them a space for learning and knowledge generation that involves negotiation and continuous exchange. The demands on organizations for innovation and change because of the competitive environment in which they live suggest new ways of thinking about what learning and knowledge are. This goes beyond what is available through formal ways of learning, to include the tacit knowledge and collective learning results of everyday social interactions. From this perspective, this paper aims to present and analyze the possibility of investigation into organizational learning from the concept of practice and in the light of ethnomethodology by examining how they articulate these ideas and to what extent they bring new ways of seeing and understanding this phenomenon. Under the lens of garfinkelian ethnomethodology, the article brings a different view to understanding organizational learning based on the concept of practice (Gherardi, 2006). The main reflections of this essay point out that organizational learning under the assumptions of ethnomethodology implies the need to think about this phenomenon through the daily practices of organizations and also discusses the demand for better systematization of ethnomethodology as a possibility for empirical research in management studies.
\end{abstract}

Key words: ethnomethodology; practice based studies; organizational learning. 


\section{Introdução}

Pensar as organizações enquanto campos simbólicos nos quais as pessoas convivem em constante interação mediadas pela linguagem e, assim, constroem significado e sentido para suas atividades cotidianas (Hatch \& Yanow, 2003) faz delas um espaço de aprendizagem e geração de conhecimento, envolvendo negociação e troca contínuas. As demandas sobre as organizações por inovação e mudança, em razão do ambiente competitivo em que vivem, sugere novas formas de pensar o que é aprender e conhecer que parece ir além do que está disponível em livros, manuais e salas de aula ou treinamento. É preciso tentar entender como as pessoas aprendem umas com as outras no cotidiano, a partir de estratégias sociais que transcendem os processos formais utilizados pelas organizações. É nessa frente que os Estudos Baseados em Prática (EBP) apresentam-se como opção para compreender, debater e discutir os processos de aprendizagem coletivos e não formais nas organizações (Gherardi, 2001, 2006; Nicolini, Gherardi, \& Yanow, 2003).

Gherardi (2006) aponta que o destaque para os EBP está no reconhecimento das ciências sociais, na limitação da racionalidade e no questionamento do paradigma funcionalista nos estudos organizacionais. Sugere que esta perspectiva abre a possibilidade de entender que é possível fazer ciência sem, necessariamente, buscar generalizações e trabalhar os fenômenos de maneira situada, considerando que a temporalidade e a historicidade têm valor significativo.

Ainda segundo a autora, esta forma de pensar as organizações valoriza o que ela coloca como knowing-in-practice, ou seja, significa que o conhecimento é situado como um processo social, humano, material, estético ${ }^{(1)}$, assim como emotivo e ético. O conhecimento nessa perspectiva é construído a partir das práticas, num processo que associa o knowing (conhecer) ao doing (fazer), em que a prática é definida como "a figura do discurso que permite que os processos de conhecer (knowing) e organizar (organizing) no trabalho estejam articulados enquanto processos históricos, materiais e indeterminados" (Gherardi, 2000, pp. 220-221).

Toda prática individual é situada num amplo campo de práticas as quais se ramificam em todas as direções, do individual para o organizacional e o institucional, assim como qualquer outro sistema complexo. Aqui a aprendizagem não é entendida enquanto processos individuais, grupais e organizacionais distintos, mas como um único processo em que todos estão contemplados simultaneamente. Assim, o campo das práticas é visto como uma composição de atividades interconectadas e em constante mudança de padrão (Gherardi, 2006).

Segundo Antonello e Godoy (2009, pp. 279-280)

Os estudos baseados em práticas partem da noção de uma realidade emergente, do conhecimento como uma atividade material, conectada a artefatos materiais: o social não só está relacionado aos seres humanos, mas também a artefatos simbólicos e culturais. A noção de prática é rica à medida que articula a noção de espaço-tempo do fazer dos atores, isto é, como práticas 'situadas', implicando incertezas, conflitos e incoerências como características intrínsecas a essas práticas. Acredita-se que esta nova noção do processo de aprendizagem organizacional pode gerar consideráveis insights em sua natureza, contribuindo também para a compreensão da micro e macrodinâmica da organização, e para o fluxo de mudança em um sistema social. Para obter esses insights é necessário, porém, repensar os métodos que devem fazer parte de nossa caixa de ferramentas, devido à natureza interpretativa do processo em questão.

Procurar entender a aprendizagem que ocorre nas organizações a partir desta perspectiva exige, no entanto, a escolha de uma metodologia que oriente o pesquisador na identificação e no exame de tais práticas. De acordo com autores representativos dos EBP (Gherardi, 2001, 2006; Nicolini et al., 2003), a etnometodologia se apresenta como uma possibilidade teórico-metodológica de investigação dos processos situados e naturalísticos de aprendizagem, geração e compartilhamento de conhecimento por meio das práticas. Na literatura nacional, Oliveira, Montenegro, Machado-da-Silva 
e Rese (2010), Oliveira e Montenegro (2012) reafirmam a ideia de que a etnometodologia se caracteriza como uma abordagem teórico-metodológica de pesquisa empírica que compartilha de pressupostos epistemológicos com os Estudos Baseados em Prática e possibilita uma nova maneira de compreender os processos de aprendizagem nas organizações.

Ten Have (2004) e Rawls (2008) - reconhecidos autores da etnometodologia enquanto estratégia de investigação - destacam que, nessa modalidade de pesquisa qualitativa, os fatos são vistos como sendo produzidos nos membros e por eles próprios em atividades práticas, ou seja, o seu interesse está na compreensão do cotidiano.

A etnometodologia surgiu, na década de sessenta, do século passado, como uma corrente da sociologia americana que buscou romper com a sociologia tradicional e seu modo de desenvolver pesquisas à luz dos paradigmas positivista e pós-positivista. Ela parte da noção de que é importante compreender e apreender como organizamos nossa existência social, analisando as práticas ordinárias no aqui e agora, sempre localizadas nas interações sociais. Para Garfinkel (2006), que foi o iniciador do movimento etnometodológico, o comportamento das pessoas é construído nas interações por meio de um processo de linguagem e negociação contínuo e situado, ou seja, não há uma estrutura rígida e imutável que orienta o agir das pessoas.

Ao tomar como base as considerações acima, o presente ensaio teórico tem como objetivo apresentar e analisar a possibilidade de investigação dos processos de aprendizagem nas organizações a partir do conceito de prática e à luz da etnometodologia, examinando como se articulam tais ideias e em que medida elas trazem novas maneiras de ver e compreender esse fenômeno.

Propor essa discussão se dá em razão: (a) da emergência dos estudos sobre aprendizagem em contextos denominados como informais (Conlon, 2004; Marsick, 2009; Marsick \& Watkins, 2001), sociais (Elkjaer, 2003, 2004) ou ainda no local de trabalho (Gherardi, 2006); (b) da valorização do conhecimento tácito nas organizações (Gherardi, 2006; Strati, 2007, 2009; Tsoukas, 2003); (c) da busca por novos métodos de pesquisa que deem conta de contribuir no acesso ao fenômeno da aprendizagem no âmbito da abordagem das práticas (Geiger, 2009; Gherardi, 2009a, 2009b; Nicolini, 2009); (d) da escassez de trabalhos sobre etnometodologia em Administração, em especial no Brasil (Oliveira, Montenegro, Machado-da-Silva, \& Rese, 2010).

Como forma de atender o objetivo do ensaio ${ }^{(2)}$, o texto parte de uma rápida apresentação das diferentes abordagens teóricas que tratam sobre o campo da aprendizagem nas organizações para, a seguir, apresentar a aprendizagem organizacional segundo a perspectiva sociológica. Dá-se ainda destaque ao conceito de prática estabelecendo sua relevância aos estudos da aprendizagem e enquanto termo fundamental e preocupação primeira da etnometodologia. A etnometodologia é descrita a partir de suas características fundamentais, estratégias e técnicas de investigação. Termina-se o texto com algumas reflexões que articulam e integram a noção de aprendizagem organizacional (a partir de um olhar sociológico), o conceito de prática e a etnometodologia, discutindo-se o potencial desta contribuição para a compreensão do fenômeno da aprendizagem nas organizações.

\section{As Múltiplas Abordagens para se Compreender a Aprendizagem nas Organizações}

A discussão sobre a importância do conhecimento para a competitividade das organizações contemporâneas não é nova, entretanto, compreender os processos de aprendizagem dos indivíduos, dos grupos de trabalho, nas organizações e entre organizações, ainda se configura como um tema relevante e inacabado (Antonello \& Godoy, 2009).

Os estudos sobre aprendizagem organizacional apresentam múltiplas abordagens tanto teóricas quanto metodológicas, o que configura o campo como amplo e complexo. De acordo com Vera (2009, p. 499), essa diversidade tem sido amplamente discutida por Easterby-Smith (1997), Easterby-Smith, 
Crossan e Nicolini (2000), Easterby-Smith e Lyles (2003), mostrando que Easterby-Smith tem desempenhado, ao longo dos anos, o papel de organizador, integrador e construtor desse campo.

Esse autor (Easterby-Smith, 1997), em uma das primeiras classificações sobre a temática, destaca que a aprendizagem organizacional se configura enquanto uma área de estudo multidisciplinar que apresenta diferentes agendas de pesquisa e conta, especialmente, com as contribuições de seis perspectivas acadêmicas que representam diferentes tradições de pensamento no campo das ciências sociais. Considerando-se que esse trabalho seminal reflete, ainda nos dias de hoje, as grandes contribuições para a constituição do campo da aprendizagem organizacional, expõe-se, a seguir, sinteticamente, cada uma delas: (a) a perspectiva da psicologia, que se concentra no desenvolvimento humano no contexto organizacional, propondo a existência de diferentes níveis ou estágios quando se trata da aprendizagem individual, a qual é influenciada pelo ambiente e pelas experiências organizacionais, e envolve a interrelação entre pensamento e ação; (b) a perspectiva das ciências administrativas, cujo foco está na aquisição e no processamento da informação na organização, com especial destaque para a criação e a disseminação do conhecimento em nível organizacional; (c) a perspectiva estratégica, que visa examinar até que ponto a aprendizagem proporciona vantagem competitiva às organizações e de que forma as organizações são capazes de se adaptar às constantes mudanças promovidas pelas próprias organizações e pelo ambiente onde estão inseridas; (d) a perspectiva da gestão da produção, com ênfase no relacionamento entre aprendizagem e eficiência organizacional, em termos de produtividade; (e) a perspectiva cultural, que estuda como a cultura em suas manifestações nacionais e organizacionais - influencia os processos e a própria natureza da aprendizagem; (f) a perspectiva sociológica, que busca o entendimento de como os sistemas sociais e as estruturas organizacionais afetam a aprendizagem que ocorre no interior das organizações, chamando atenção para os aspectos relacionados ao poder, à política e aos conflitos que constituem parte da realidade organizacional.

As perspectivas (a) e (f), em especial, têm se enriquecido ao adotar abordagens paradigmáticas apoiadas nas tradições do interpretacionismo e do construcionismo, assim como do pós-modernismo crítico, conforme destacam Shipton (2006) e Bapuji, Crossan e Rouse (2005), ao analisarem a literatura internacional, e Antonello e Godoy (2009), ao refletirem sobre o campo da aprendizagem organizacional no Brasil. Embora, em ambos os casos, ainda se note um predomínio de estudos empíricos forjados no seio dos paradigmas positivista e pós-positivista (Antonello \& Godoy, 2009; Bapuji, Crossan, \& Rouse, 2005) é fundamental estar atento para outras possibilidades que poderão dar uma contribuição significativa ao entendimento do tema, superando alguns desafios que este campo de estudos vem enfrentando ao longo de sua trajetória.

Como relatam Bapuji et al. (2005), ao analisar a produção acadêmica internacional, no período de 1981 a 2004, os estudos empíricos realizados estão fortemente associados às metodologias quantitativas (61\% dos artigos examinados), em detrimento das metodologias qualitativas (que representam 35\%). Considerando esse acentuado foco nas metodologias de orientação positivista e pós-positivista, os autores alertam que tal fato pode limitar as interpretações e os insigths decorrentes das pesquisas empíricas sobre o fenômeno. Para eles, uma vez que a aprendizagem pode ser estudada a partir de múltiplas lentes teóricas, a investigação sobre ela também deveria apresentar uma maior diversidade no âmbito dos caminhos metodológicos escolhidos.

Para autores como Antonello e Godoy (2009, 2010), Gherardi (2006) e Nicolini, Gherardi e Yanow (2003), essa contribuição poderá vir da adoção da corrente de pensamento da aprendizagem baseada na prática. De acordo com Antonello e Godoy (2010, p. 326), essa vertente

ressalta que a aprendizagem não pode ser considerada somente como processo individual. A aprendizagem é compreendida pelo emergir de relações e interações das pessoas com os elementos sociais e materiais de contextos particulares. Assim ... contexto é considerado a partir de suas divisões de trabalho e relações de poder, ambiente, cultura, linguagem, dentre outros. Aqui se revela a aprendizagem vista enquanto processo, em todas as suas tensões e fluidez. 
Nesse sentido, no ensaio aqui apresentado, a perspectiva sociológica merece destaque, pois aprofunda e desenvolve conceitos fundamentais ao entendimento dos EBP e da etnometodologia enquanto possibilidade investigativa para o estudo do fenômeno. A abordagem sociológica, no entanto, é melhor descrita por Gherardi e Nicolini (2001) sendo objeto do item a seguir.

\section{As Abordagens Sociológicas da Aprendizagem Organizacional}

Do ponto de vista social, a aprendizagem é vista como "algo produzido e reproduzido nas relações sociais dos indivíduos, quando eles participam de uma sociedade" (Gherardi \& Nicolini, 2001, p. 47). Está integrada no cotidiano das pessoas e é, em grande parte, oriunda das relações sociais informalmente estabelecidas. Assim, é possível dizer que toda atividade, toda prática desenvolvida na vida dos indivíduos, constitui-se numa oportunidade para a aprendizagem. A prática adquire então, para esses autores, lugar de destaque no âmbito das perspectivas sociológicas, sendo definida como "um sistema de atividades no qual o saber não está separado do fazer e das situações, podendo ser chamado de conhecimento coproduzido por meio da ação" (Gherardi \& Nicolini, 2001, p. 49).

Para apresentar as narrativas de aprendizagem organizacional tendo como eixo o enfoque sociológico, Gherardi e Nicolini (2001) se apropriam das quatro tradições identificadas por Collins (1994), acrescentando o pós-modernismo que, mesmo não sendo considerado uma tradição, pode se constituir num arcabouço teórico importante para conduzir a reflexão acerca do conhecimento enquanto prática discursiva. A Tabela 1, exposta a seguir, sintetiza o pensamento dos autores.

Tabela 1

As Tradições Sociológicas e as Narrativas de Aprendizagem Organizacional (AO)

\begin{tabular}{l|l}
\hline Tradição Sociológica & Narrativa de Aprendizagem organizacional \\
\hline Tradição do Conflito & $\begin{array}{l}\text { AO como ideologia de um grupo de poder. } \\
\text { AO como política de mobilização de recursos de poder e conflito. } \\
\text { AO como tentativa de gerenciar a tensão entre a racionalidade substantiva e a formal. }\end{array}$ \\
\hline Racional/Utilitária & $\begin{array}{l}\text { AO como resolução de problemas, quando o desempenho da organização não conhece } \\
\text { os níveis de aspiração. } \\
\text { AO como a ativação da troca no trabalho em rede. } \\
\text { AO como aprendizagem ecológica, localizada e distribuída pelos multiatores dentro } \\
\text { das rotinas, ao invés de dentro da mente dos indivíduos. }\end{array}$ \\
\hline $\begin{array}{l}\text { Durkheiniana } \\
\text { Aefine as condições que facilitam ou dificultam a aprendizagem organizacional. } \\
\text { AO engendra (ou não) mudanças nas organizações em decorrência dos diferentes } \\
\text { contextos de socialização presentes nos ambientes organizacionais. } \\
\text { AO como socialização de códigos culturais específicos. Conceitua aprendizagem } \\
\text { organizacional como socialização, que sintetiza conteúdos de diferentes ordens da } \\
\text { sociedade, porque as ações seletivas em sua chance de vida criam um senso de determinar } \\
\text { inevitavelmente ordem social e restringir o resultado de mudança que é permitida. }\end{array}$ \\
\hline Microinteracionista \\
$\begin{array}{l}\text { AO como transmissão de conhecimento dentro das comunidades ocupacionais. } \\
\text { AO como rótulo que produz uma realidade socialmente construída e é produzida por } \\
\text { esta realidade. }\end{array}$ \\
. AO como prática discursiva.
\end{tabular}

Nota. Fonte: traduzido de Gherardi, S., Nicolini, D. (2001). The sociological foundations of organizational learning (p. 46). In M. Dierkes, A. Berthoin Antal, J. Child, \& I. Nonaka (Orgs.), The handbook of organizational learning and knowledge (pp. 35-60). Oxford: Oxford University Press. 
A Tabela 1 mostra que existem formas distintas de entender o processo de aprendizagem, algumas delas com um posicionamento epistemológico mais funcionalista como a tradição Durkheiniana, outras estruturalistas como a tradição utilitarista, posturas críticas como a tradição de conflitos e outras mais interpretativistas como as tradições microinteracionista e pós-moderna, de maior interesse para este trabalho.

$\mathrm{Na}$ tradição microinteracionista, a aprendizagem organizacional é vista como situada e o conhecimento gerado a partir de negociações, rupturas e descontinuidades. $\mathrm{O}$ processo de construção do conhecimento é heterogêneo e fragmentado, sendo a sociedade constituída por meio dos significados atribuídos às práticas cotidianas de seus membros. A linguagem, nesse caso, não se resume a uma forma de expressão das relações sociais, mas enquanto meio para a criação das mesmas. Nesse sentido, conforme afirma a tradição pós-moderna, o discurso organizacional não usa a linguagem como um espelho da realidade ou dos estados mentais dos indivíduos. A linguagem aqui deve ser entendida como metafórica e permeada de contradições e incoerências de natureza local, e que se expressa por meio de instáveis e múltiplos discursos. A aprendizagem organizacional nessa tradição é, então, vista como prática discursiva. O discurso da aprendizagem organizacional é entendido como inserido nas relações de poder que moldam a subjetividade dos atores sociais, tornando-o instável, incompleto e sempre aberto a novas interpretações.

Segundo Gherardi e Nicolini (2001), ao utilizar uma ontologia construcionista e uma epistemologia interpretativista, a aprendizagem organizacional passa a ser vista como conversação e, nesse contexto, os conceitos sociológicos de participação e reflexividade assumem importância fundamental.

Antonello e Godoy (2010, p. 316) destacam que para Gherardi e Nicolini (2001):

O conceito de participação lança luzes no fato de que a aprendizagem não ocorre somente na mente dos indivíduos, mas origina-se e sustenta-se na participação deles em atividades sociais. A lógica da prática não traça distinção entre conteúdo e objeto; ao invés disto, envolve o saber como ser competente num ambiente.... A reflexividade, em contraste, relata o momento particular da separação entre o conteúdo do conhecimento e o seu objeto do conhecimento. Isto instiga a organização, envolvida no processo social, a extrair o conhecimento teórico oriundo do conhecimento prático e, então, transformá-lo em conhecimento normativo, produzindo as condições necessárias para a operacionalização deste conhecimento.

O conceito de reflexividade está vinculado ao de participação na medida em que a reflexividade ocorre a partir do momento no qual o fluxo da experiência é interrompido, buscando-se rever ações anteriores e refletir sobre a existência de outras formas de vê-las e entendê-las, dando origem, portanto, à institucionalização do conhecimento.

Neste sentido, conforme propõem Nicolini et al. (2003), o estudo da aprendizagem organizacional deve voltar-se ao exame dos microprocessos que informam e constituem as práticas contínuas dos atores em ambientes sociais diversos. "Nesse contexto, aprender se torna ato reflexivo, por meio de olhar os sistemas por seus atos passados e os planos de seu futuro" (Antonello \& Godoy, 2010, pp. 326-327).

\section{O Conceito de Prática nos Estudos de Aprendizagem Organizacional}

Como verificado no item anterior, o conceito de prática surge no interior das tradições sociológicas de aprendizagem e enfatiza a compreensão situada do aprender, destacando a importância do contexto nesse processo. A questão da prática é central para o desenvolvimento de uma série de abordagens que se convencionou chamar de Estudos Baseados em Prática (EBP), e que foram se estabelecendo e organizando enquanto objeto de pesquisa de um grupo de acadêmicos, na sua maioria europeus, da área de estudos organizacionais a partir de 1998. É fundamental, portanto, que 
seja explicitada, iniciando pela evidência de que o conceito de prática para esses acadêmicos está relacionado ao estudo da organização da vida cotidiana das pessoas no trabalho a partir de um conjunto de atividades coletivas que promovem a construção intersubjetiva do senso comum, principal objeto de estudo da etnometodologia (Garfinkel, 2006; Gherardi, 2006).

Gherardi (2009a, 2009b) entende as práticas como as formas de fazer de uma sociedade. Por meio da reflexividade, as práticas produzem e reproduzem a sociedade, são construções coletivas situadas e reconhecidas apenas dentro de uma intersubjetividade. Para a autora (2009b, p. 536), "prática é um conceito analítico que possibilita a interpretação de como as pessoas alcançam ativamente "ser no mundo"". Uma prática não é reconhecível fora do significado criado a partir da intersubjetividade. Desta forma, o entendimento de práticas não é sinônimo de hábito ou rotina de atividades de forma isolada, mas um padrão social recorrente sustentado pelas ações reproduzidas no seio de uma sociedade (Gherardi, 2009b).

Embora Gherardi (2006) considere que uma definição direta de prática implica em um reducionismo, enfatiza que é necessário buscar os fundamentos que servem de base para entender a prática. Desta maneira, utilizando como referência pressupostos fenomenológicos e etnometodológicos, Gherardi (2006, p. 34) define "uma prática como um modo relativamente estável no tempo e socialmente reconhecido de ordenar elementos heterogêneos em um conjunto coerente".

A partir dessa definição, a autora faz referência a quatro características fundamentais para o entendimento do termo prática. Primeiro ressalta o aspecto holístico e qualitativo de uma prática, destacando-a como um conjunto de atividades que adquire significado e torna-se reconhecido enquanto unidade. Além disso, é importante pontuar que tal conjunto de atividades só assume seu significado no contexto de uma ação reconhecida e situada por determinados agentes nela envolvidos.

Em segundo lugar, destaca o relacionamento da prática com a temporalidade. Para a autora, as práticas devem ser repetidas muitas vezes para que sejam reconhecidas socialmente como um modo habitual de se fazer as coisas. No entanto, a reprodução do mundo social não se dá de forma mecânica, mas pode ser entendida como um processo que, ao mesmo tempo em que mantém as formas originais, permite, simultaneamente, a introdução de mudanças. As práticas têm uma história e persistem no tempo, apesar de sua contínua adaptação às circunstâncias.

Como terceira característica, a autora enfatiza que as práticas precisam ser reconhecidas socialmente e pressupõem a existência de um sistema institucional que dê sustentação às normas que as orientam.

Por fim, pode-se dizer que elas constituem um modo de organização do mundo. Quando as práticas são desempenhadas, elas introduzem uma determinada ordenação de elementos humanos e não humanos que, apesar de frágil, temporária e constantemente ameaçada pela desordem, torna-se parte de uma rede de práticas ancoradas umas às outras.

Apesar da existência de certa diversidade de abordagens dentro dos EBP, há algumas características marcadas por um vocabulário comum que identifica essa linha de estudos. Uma delas é a presença de verbos utilizados no gerúndio como uma forma de evidenciar o caráter dinâmico e processual das práticas, ou seja, algo sempre em construção e movimento (Nicolini et al., 2003). Como na Língua Portuguesa a utilização do gerúndio ocorre em ocasiões muito específicas, durante este ensaio será comum à manutenção dos principais verbos utilizados nos estudos de prática no idioma inglês como, por exemplo, organizing, translating, doing, learning e kwowing. Essa opção visa não obstruir o entendimento adequado das palavras em certos contextos que são importantes, no arcabouço teórico utilizado. Assim como os verbos, alguns substantivos também são comumente utilizados nos EBP por sua indicação de ação, entre os quais é possível citar atividade, alinhamento, construção e oficialização (Nicolini et al., 2003).

Esse vocabulário é utilizado porque os EBP focalizam o que as pessoas fazem, de maneira a entender como e sob quais condições as ações são realizadas. É importante ressaltar também que o termo social, dentro do contexto das práticas, refere-se a uma condição de grupo, ou seja, remete à 
ideia de que learning e knowing não estão nas mentes das pessoas, mas são oriundos de uma construção coletiva. Juntamente com a ideia de social está também o termo situado, isso porque todas as abordagens que utilizam as práticas, como forma de observação, partem de um entendimento de que elas são construídas e ocorrem em certo tempo e espaço, ou seja, são situadas (Nicolini et al., 2003). Uma compreensão mais acurada dos termos learning, knowing e organizing - no âmbito dos EBP faz-se então necessária.

O conceito de learning está sempre associado a uma aprendizagem coletiva considerada como um processo por meio do qual os atores sociais tornam-se membros de um grupo. Mesmo quando se está falando de uma pessoa, aprender implica, necessariamente, uma condição de grupo, seja enquanto possibilidade de ingresso e efetivação como membro (no caso dos novatos), ou como uma forma negociada entre os participantes de um grupo de produzir, reproduzir e/ou modificar as práticas que os identificam (Gherardi, 2001; Gherardi \& Nicolini, 2001).

O conceito de knowing é utilizado para evidenciar a dinâmica existente no conhecimento, quando ele está associado à prática. $\mathrm{O}$ knowing, como representação, transmite a ideia de uma rede social tecida em torno de um domínio de conhecimento, ou seja, uma prática. Tomar contato com o knowing significa tornar-se um insider em uma comunidade de prática. Entende-se aqui que o conhecimento é mediado pelas relações sociais e o knowing é parte de uma adequação a um hábito social (Gherardi, 2001). Para Wenger (2000), o knowing deve ser entendido como um ato de participação em um complexo sistema social de aprendizagem, em que aprender e conhecer são ações interligadas. Ele se constitui num processo que resulta no knowledge, ou seja, no conhecimento, em sua forma institucionalizada, sendo considerado condição essencial para a aprendizagem de uma prática. A expressão knowing-in-practice refere-se, então, ao momento de interação das pessoas com as práticas, de modo que elas vão se apropriando dessas práticas de forma tácita. Está associada ainda aos conceitos de currículo de aprendizagem e currículo situado, em que o primeiro diz respeito ao conjunto de conhecimentos que uma pessoa precisa aprender para assumir a condição de membro de uma comunidade (como, por exemplo, em uma profissão), e o segundo estreita esse entendimento para o contexto de um grupo ou organização específica (por exemplo, ser engenheiro de uma determinada empresa); ambos reforçando a ideia de que a aquisição dos conhecimentos para a aquisição de uma prática ocorre de maneira situada (Gherardi, 2006).

Já o conceito de organizing distingue a atividade que mobiliza os conhecimentos utilizados e utilizáveis em uma prática. Implica a articulação entre sujeitos (aqui entendidos como membros, coletividade, organização e/ou instituição) e objetos (denominados também de artefatos ou elementos não humanos) em torno de uma prática (Gherardi, 2006). Significa o processo organizativo de uma coletividade que, através de suas práticas, poderá ser identificada enquanto organização.

Para Nicolini et al. (2003), os EBP oferecem uma nova maneira de estudar a aprendizagem e a geração de conhecimento nas organizações, por estarem fundamentados em uma específica proposta ontológica e epistemológica. A ontologia, nesse caso, configura-se a partir de um vocabulário que apresenta uma visão do mundo como relacionalmente constituído, assemelhando-se a uma rede de elementos heterogeneamente conectados e perpetuados por um processo ativo de organização de sentido. Nesse contexto, as práticas podem ser associadas a um trabalho de bricolagem que reúne elementos materiais, mentais, sociais e culturais em um contexto situado.

Nicolini et al. (2003) sugerem uma classificação com quatro tradições dentro dos EBP, embora afirmem ser esta apenas uma maneira de enxergar as perspectivas existentes no campo de estudos que emprega as práticas como perspectiva. Contudo, a classificação feita pelos estudiosos contribui para que seja possível um melhor entendimento dos estudos nessa área. Gherardi, em seu trabalho de 2006, introduz mais uma tradição que é a das práticas em local de trabalho (workplace studies). Para facilitar e resumir as principais características de cada uma das tradições, elaborou-se a Tabela 2. 
Tabela 2

\title{
Tradições nos Estudos Baseados em Prática
}

\begin{tabular}{llll}
\hline Tradição & Base teórica & Autores Relevantes & Descrição genérica \\
\hline Cultural Interpretativa & Julgamento estético/ & Yanow e Strati & $\begin{array}{l}\text { Mostram como os artefatos e as } \\
\text { interações sustentam os significados e o } \\
\end{array}$ \\
& Transmissão cultural & & $\begin{array}{l}\text { conhecer na prática sem um processo de } \\
\text { intervenção. O julgamento estético é } \\
\end{array}$ \\
& & realizado a partir de alguém que faz \\
& & considerações sobre as práticas \\
& & relacionadas aos seus sentidos.
\end{tabular}

$\begin{array}{lll}\begin{array}{l}\text { Comunidades de } \\ \text { prática }\end{array} & \begin{array}{l}\text { Interacionismo } \\ \text { simbólico/ habitus }\end{array} & \begin{array}{l}\text { Wenger e Gomez; } \\ \text { Bouty e Drucker- } \\ \text { Godard }\end{array}\end{array}$

Teoria da atividade cultural e histórica

\section{Sociologia da translação/}

Teoria ator-rede

Estudos no local de trabalho (workplace studies)

\author{
Psicologia cultural de \\ Vygostsky/ Praxis de \\ Marx / elementos do \\ interacionismo \\ simbólico
}

\begin{abstract}
Combina elementos das outras abordagens com a distribuição do poder de Foulcault e a construção de significado de Wittgenstein.
\end{abstract}

Engeström, Puonti e Seppänen; Blackler, Crump e McDonald

Law, Singleton e Suchman; Gherardi e Nicolini

$$
\begin{aligned}
& \text { Comunidades surgem e crescem da } \\
& \text { interação entre competência e } \\
& \text { experiência pessoal, em um contexto de } \\
& \text { engajamento com uma prática comum, } \\
& \text { ou seja, as práticas sustentam as } \\
& \text { comunidades e os novos membros são } \\
& \text { admitidos em um processo de } \\
& \text { legitimação periférica. As práticas são } \\
& \text { entendidas como estruturas (habitus). }
\end{aligned}
$$

Nesta abordagem, as atividades são culturalmente situadas e mediadas pela linguagem e artefatos tecnológicos. As atividades são sempre desenvolvidas em comunidades e implicam em divisão do trabalho entre os membros. O trabalho orienta as práticas e a mudança destas.

Uma interpretação sensitiva baseada na noção de que o social não é nada mais do que um padrão de rede de materiais heterogêneos que incluem não apenas pessoas, mas também máquinas, animais, textos, moeda, arquiteturas, entre outros elementos que se ligam por um processo de ordenação. O foco está em como o conhecimento é construído, mantido e perpetuado.

\author{
Relação da tecnologia Suchman e Borzeix \\ na constituição do \\ ambiente de trabalho/ \\ tecnologia como uma \\ prática social
}

Considera o trabalho uma atividade em que sujeitos e objetos, presentes em um conjunto, constituem e dão sentido para as atividades que emergem da sua interação.

Nota. Fonte: elaborado pelos autores com base em Nicolini, D., Gherardi, S., \& Yanow, D. (2003). Introduction: toward a practice-based view of knowing and learning in organizations. In D. Nicolini, S. Gherardi, \& D. Yanow (Orgs.), Knowing in organizations: a practice-based approach (pp. 3-31). London: Sharpe; e Gherardi, S. (2006). Organizational knowledge: the texture of workplace learning (pp. 189-196). Oxford: Blackwell Publishing.

De acordo com os próprios autores, não há uma fronteira exata entre as tradições. Assim, também não é possível afirmar que haja uma teoria pronta acerca das práticas, tratando-se apenas de contribuições na construção desse campo de estudos e pesquisas.

Em relação ao arcabouço epistemológico e às abordagens metodológicas, Gherardi (2001, 2006, 2009a) Nicolini et al. (2003), Nicolini (2009) e Suchman (2003) evidenciam que os EBP, no contexto das organizações, têm na etnometodologia uma base teórica fundamental e orientadora de suas investigações empíricas. 


\section{A Etnometodologia}

A etnometodologia tem como principal referência e iniciador do movimento o sociólogo Harold Garfinkel, que elaborou suas ideias a partir de elementos encontrados no interacionismo simbólico, na obra de Parsons e na fenomenologia de Husserl e de Schutz. Outra influência significativa é o legado de Wittgenstein em relação aos jogos de linguagem. Sua obra mais famosa é Studies in Ethnomethodology, publicada em 1967 (Coulon, 2005; Rawls, 2008; Ten Have, 2004).

Para Garfinkel, a sociologia: não devia ser entendida como uma ciência positivista em que os fatos, de acordo com Durkheim, são estabelecidos a priori por uma estrutura estável independentemente da História e de maneira objetiva. Garfinkel propunha uma sociologia que tivesse uma postura interpretativa que valorizasse a subjetividade em que descrever uma situação é construíla. Nessa linha de pensamento, a sociologia considera atos sociais como realizações práticas que não se constituem em um objeto estável, mas como um produto da atividade contínua das pessoas que colocam em prática o seu saber fazer (knowing e doing), seus procedimentos e suas regras de conduta. Em outras palavras, trata-se de uma sociologia profana (Coulon, 2005).

O termo etnometodologia refere-se à metodologia de todo dia, em que etno significa membro de um grupo ou do próprio grupo em si e metodologia se refere aos métodos dos membros. Assim, a etnometodologia diz respeito às efetivas práticas situadas em determinados contextos (Psathas, 2004), em outras palavras, o estudo dos métodos que os membros de um grupo utilizam para produzir ordens sociais reconhecíveis (Rawls, 2002). A base da etnometodologia está nas atividades práticas pelas quais os atores produzem e reconhecem as circunstâncias em que estão inseridos, devido ao sentido que as práticas têm para eles (Maynard \& Clayman,1991). Assim, o principal objetivo etnometodológico é investigar os processos de realização das atividades, preocupando-se com o comportamento dos membros envolvidos no contexto de uma coletividade, um grupo ou uma organização (Heritage, 1987; Rawls, 2008).

Coulon (2005, p. 32) define a etnometodologia como "a busca empírica dos métodos empregados pelos indivíduos para dar sentido e, ao mesmo tempo, realizar suas ações de todos os dias: comunicar-se, tomar decisões, raciocinar". Para ele, a etnometodologia analisa as crenças e os comportamentos do senso comum como componentes necessários para toda conduta socialmente organizada.

Ao buscar realizar uma síntese sobre a etnometodologia, Coulon (2005, p. 34) afirma:

No lugar de formular a hipótese de que os atores seguem as regras, o interesse da Etnometodologia consiste em colocar em dia os métodos empregados pelos atores para 'atualizar' ditas regras. Isso as faz observáveis e descritivas. As atividades práticas dos membros, em suas atividades concretas, revelam as regras e os procedimentos. Dito isso de outra forma, a atenta observação e análise dos processos levados a cabo nas ações permitiriam colocar em dia os procedimentos empregados pelos atores para interpretar constantemente a realidade social para inventar a vida em uma bricolagem permanente.

Esta frase, colocada pelo autor, destaca o valor que as atividades práticas têm para a etnometodologia, ou seja, a importância de adotar uma postura investigativa a partir de uma metodologia etnometodológica é buscar compreender a sociedade tomando como referência as práticas cotidianas de um grupo ou de uma comunidade. Isso implica dizer que o saber não se constrói com observações imparciais, fora do contexto do objeto de estudo, mas é na interação com o meio, na busca por compartilhar o sentido, que o significado das práticas para a construção de uma interpretação coletiva da realidade se dá.

Coulon (2005), Heritage (1987), assim como Francis e Hester (2005) apontam cinco conceitoschave para a investigação etnometodológica, que são as noções de: prática (realização), 
indicialidade, reflexividade, accountability e membro. É importante pontuar que tais noções já estão evidenciadas no texto seminal de Garfinkel (2006).

O conceito de prática, ou realização, indica que a preocupação central da etnometodologia é com as atividades práticas, corriqueiras da vida cotidiana. Ela busca examinar, empiricamente, os métodos que os indivíduos empregam para atribuir sentido e, ao mesmo tempo, realizar suas ações cotidianas, sejam elas triviais ou eruditas (Heritage, 1987). A etnometodologia parte daquilo que é conhecido como senso comum para analisar as crenças e os comportamentos dos membros de um grupo, considerando que todo comportamento é socialmente organizado. A partir da ideia de que a realidade social é constantemente criada pelos atores que dela fazem parte, a etnometodologia não trabalha com a hipótese de que os atores sociais sempre seguem regras, mas está preocupada em examinar os métodos que eles usam para mudar, atualizar, adaptar tais regras, interpretando e inventando, constantemente, a realidade social. (Coulon, 2005).

A indicialidade, um termo técnico que tem origem na linguística, aponta que, ao mesmo tempo em que uma palavra tem um significado, de certa forma genérico, esta mesma palavra possui significação distinta em situações particulares. Assim, a sua compreensão precisa, em alguns casos, de que as pessoas busquem informações adicionais que vão além do simples entendimento genérico da palavra (Coulon, 2005). Essa ideia de indicialidade indica que uma palavra pode apresentar um sentido independentemente de suas condições de uso e enunciação, ou seja, a linguagem é uma produção coletiva que assume significados diversos, dependendo de fatores contextuais como a biografia de quem fala, sua intenção imediata, seu relacionamento com quem ouve e suas conversações passadas. Para Garfinkel (2006), a linguagem natural, ordinária, por meio da qual as pessoas se expressam em seu dia a dia, é profundamente indicial, pois, para cada ator social, o significado de sua linguagem cotidiana depende do contexto em que ela se manifesta.

Já o conceito de reflexividade está relacionado aos efeitos das práticas de um grupo, em outras palavras, o processo de construção contínua de um grupo, ou comunidade, por meio de suas atividades práticas. Ao mesmo tempo em que se constituem nos resultados da interação entre os membros, imprimem influências sobre esses mesmos indivíduos componentes do grupo (Francis \& Hester, 2004). Trata-se de um processo em que ocorre uma ação e, ao mesmo tempo, produz uma reação sobre os seus criadores. A reflexividade não deve aqui ser confundida com reflexão, pois a reflexividade, no entender de Garfinkel, designa as práticas que, ao mesmo tempo em que descrevem também constituem um quadro social a partir do qual os atores exprimem os significados de seus atos e pensamentos (Coulon, 2005).

Coulon (2005) descreve a ideia de accountability no contexto da etnometodologia, dizendo que ela se refere a uma condição reflexiva e racional. Para Garfinkel (2006, p. 1) "os estudos etnometodológicos analisam as atividades cotidianas dos membros como também dos métodos que fazem estas atividades visivelmente racionais e relatáveis a todos os fins práticos, isto é, descritíveis (accountable), enquanto organização ordinária das atividades de todos os dias".

Considera-se aqui que as atividades são inteligíveis e podem ser descritas, de outra maneira, é como o grupo estudado descreve as atividades práticas a partir das referências de sentido e significado que o próprio grupo possui. Assim, a accountability pode ser considerada como uma justificativa do grupo para determinada atividade e conduta. Romero (1991) coloca que a accountability é a explicação que os atores utilizam para descrever, analisar, criticar e idealizar situações específicas.

O quinto conceito chave na etnometodologia é a concepção de membro. Com alguma diferença em relação ao que Parsons entendia como membro, a ideia de um indivíduo pertencente a um grupo, Garfinkel entende que o membro é aquele que compartilha da linguagem de um grupo. Nas palavras de Coulon (2005, pp. 51-52),

um membro não é apenas uma pessoa que respira e que pensa. É uma pessoa dotada de um conjunto de procedimentos, de métodos, de atividades, de savoir-fare, que a fazem capaz de inventar dispositivos de adaptação para dar sentido ao mundo que a rodeia. 
A partir das considerações de Coulon (2005), é possível entender que o membro na concepção de Garfinkel induz a uma condição de ser do e no grupo e não apenas de estar.

Esses cinco conceitos-chave da etnometodologia contribuem para que o pesquisador, ao adotar essa metodologia, possa ir a campo com um pré-entendimento de que, para acessar o fenômeno desejado, é preciso participar efetivamente do cotidiano do grupo para que seja possível compreender o processo de construção das práticas, juntamente com os seus significados. Para Garfinkel, trata-se de praticar a sociologia profana, ou seja, a noção de profana está relacionada à ênfase que se dá em compreender a construção do cotidiano, assim como valorizar a organização naturalística de um grupo social por meio de suas práticas. Garfinkel (2006) entende que as práticas são situações definidas por expectativas constituídas, não nas pessoas, mas em uma ordem de ações em que suas propriedades estão situadas em grupos e métodos que definem esse grupo, ou seja, não está na organização ou nas motivações individuais para a criação de sentido (sensemaking).

Os estudos etnometodológicos, conhecidos também como workplace studies, tratam os trabalhadores - e não os pesquisadores, como experts - buscando pela compreensão de como o trabalho é realizado e de como os problemas são detectados e resolvidos por eles (Rawls, 2008). Essa premissa é que, justamente, gera a maior parte das críticas a etnometodologia de Garfinkel, uma vez que, na visão dos críticos, os escritos do autor são altamente condensados e, por vezes, opacos. Embora dotadas de fortes continuidades teóricas, estas não se apresentam de maneira evidentemente articuladas quando comparadas à sociologia clássica de Durkheim, por exemplo (Heritage, 1987). Coser (1975) discute que a etnometodologia constitui-se como um método sem substância, que sugeria uma espécie de sociologia vale tudo.

Além das críticas trazidas por Heritage (1987) e Coser (1975), outros autores também apontam alguns limites sobre a etnometodologia. Sharrock e Randall (2004) discutem a falta de preocupação dos etnometodólogos na reprodutibilidade das pesquisas realizadas, assim como na generalização dos resultados. Marcon e Gopal (2008) trazem em seu trabalho a discussão de que a etnometodologia supostamente desconsidera a questão da crítica e das relações de poder nos grupos analisados sob esta abordagem.

\section{Estratégias e Técnicas de Investigação na Etnometodologia}

Para Rawls (2008), a postura do etnometodólogo implica em não formular perguntas e problemas antes de ingressar no campo de investigação. O pesquisador deve estar atento aos métodos que os participantes utilizam para fazer algo inteligível, ou seja, não há espaço para concepções $a$ priori. A ideia é utilizar um conceito semelhante ao de suspensão da fenomenologia para que seja possível a compreensão de como são as práticas cotidianas e de quais o significado e o sentido das mesmas para os membros do grupo em investigação. Garfinkel (2006) denomina este processo como indiferença etnometodológica e esclarece que a principal preocupação do pesquisador, ao estar no campo, deve ser de observar e compreender como os membros de um grupo agem a partir de pontos de vista, crenças e referências sociais que possuem.

Oliveira et al. (2010) colocam que os procedimentos utilizados pelos etnometodólogos não são exclusivos ou mesmo novos, e fazem parte do patrimônio da sociologia qualitativa moderna. Destacam que muitos dos instrumentos de pesquisa utilizados são emprestados da etnografia, embora num estudo de caráter etnometodológico devam ser aplicados com matizes próprios, que levem em conta seus elementos fundadores, como poderá ser observado na exposição a seguir. Embora a discussão das diferenças entre etnografia e etnometodologia não faça parte do escopo deste trabalho, recomenda-se aos interessados a leitura de Ten Have (2004), Francis e Hester (2004), Pollner e Emerson (2001). 
A estruturação de um trabalho etnometodológico pode ser realizada a partir de quatro estratégias, como aponta Ten Have (2004):

1. experimentos de desarrumação: estão relacionados à criação artificial de situações em que os membros têm que realizar um trabalho de criação de sentido extra em razão de reparar expectativas faltantes ou contraditórias no seu repertório (esta estratégia era utilizada por Garfinkel para ensinar a seus alunos os pressupostos da etnometodologia);

2. estudos feitos pelos pesquisadores de suas próprias práticas e sua criação de sentido: práticas em que os pesquisadores se colocam em uma situação extraordinária, como tentar realizar uma tarefa muito difícil, algo fora do seu âmbito de atuação ou conhecimento;

3. utilização de métodos de campo para estudar situações naturais: em que a criação de sentido é também compartilhada com os participantes locais;

4. gravar e transcrever atividades ordinárias: com o intuito de estudar a constituição dos métodos utilizados pelos participantes na construção das suas práticas.

Para Ten Have (2004), estas estratégias são sugestões de forma que podem ser utilizadas para o acesso ao fenômeno que será estudado. O autor complementa dizendo que, além dessas estratégias, a pesquisa deve ser dividida em duas fases: a primeira refere-se ao entendimento das atividades em estudo, focando-se a criação de sentido das práticas atribuídas pelos atores sociais que as compartilham; e a segunda, à análise dos métodos utilizados na primeira fase.

Para dar conta das estratégias acima apontadas, algumas técnicas de coleta de dados estão mais diretamente associadas às características de um estudo etnometodológico: observação direta, observação participante, diálogos (conversas informais), entrevistas, gravações em vídeo, projeção do material gravado para os próprios atores (participantes), gravações em áudio, notas de campo, além de debates com os participantes sobre os materiais produzidos (Coulon, 2005; Garfinkel, 2006; Oliveira et al., 2010; Rawls, 2008; Ten Have, 2004).

Dentre o repertório acima apresentado, assumem importância fundamental a observação participante, as notas de campo e as conversas informais. A observação participante destaca-se nos estudos etnometodológicos por possibilitar ao pesquisador a apropriação da realidade vivida de um determinado grupo, a partir da descrição e da interpretação de suas práticas (Ten Have, 2004). Rawls (2008) corrobora a importância do trabalho de campo e aponta que as anotações ali realizadas podem revelar características ordenadas (práticas), quando o pesquisador é treinado para observá-las e as notas de campo possibilitam a preservação dessas características. Entretanto, há algo essencialmente importante em relação à observação na etnometodologia. O pesquisador deve sempre ter em mente que não se pode observar o fenômeno com uma postura carregada de pressupostos a priori, uma vez que os experts do fenômeno pesquisado são os participantes, e o pesquisador tem por objetivo se apropriar das práticas ali existentes. Para Francis e Hester (2004, p. 26), as "observações não são o fim da investigação, elas são o início para o que é chamado de "análise constitutiva"'. A análise constitutiva se refere a como são ordenadas as características do fenômeno pesquisado, ou seja, é a análise de como são construídas as práticas.

Francis e Hester (2004) e Ten Have (2004) destacam ainda o papel das conversas informais na obtenção de informações, uma vez que elas possibilitam ao pesquisador interagir com as pessoas de maneira mais natural. Além disso, ao mesmo tempo em que o pesquisador está conversando com as pessoas, pode acompanhar o trabalho que elas estão desenvolvendo. $\mathrm{O}$ caráter formal de uma entrevista é, então, abandonado e procura-se colocar as pessoas em uma condição mais natural, que propicie a narração dos temas que vão emergindo.

Para a análise dos dados construídos no campo, o pesquisador necessita ter segurança de que compreende os pressupostos e os significados que os participantes possuem para conseguir escrever um relatório com característica etnometodológica. A atenção em relação a esse ponto é colocada a partir da necessidade que os pesquisadores têm de compartilhar da linguagem dos participantes, como 
colocam Ten Have (2004) e Francis e Hester (2004). Tal condição se faz necessária uma vez que, se o pesquisador não conhece ou não entende nada das práticas e dos membros estudados, ficam sensivelmente diminuídas as condições de interpretação e, consequentemente, um compartilhamento de sentido e significado com os participantes. Ao levar em consideração essa necessidade, uma pista de como superar essa condição é buscar realizar estudos em espaços em que o pesquisador esteja familiarizado, assim um possível tempo extenso de um processo de apropriação da linguagem encontrada no campo é evitado ou diminuído.

Em relação a como interpretar, analisar e categorizar os dados obtidos no campo, não há uma regra a ser seguida no âmbito da etnometodologia. O importante é o pesquisador ter segurança de que as interpretações realizadas correspondem àquilo que os participantes compartilham enquanto significado e sentido. Ten Have (2004) coloca que não existe uma única maneira de se fazer etnometodologia. Para o autor, qualquer ação ou invenção criativa é bem-vinda na tentativa de acessar o fenômeno de interesse, desde que estejam alinhadas com os pressupostos dessa perspectiva.

Essa característica, ao mesmo tempo em que possibilita uma flexibilidade na análise e na interpretação dos dados, gera também dúvidas e críticas em relação a uma falta de estruturação metodológica clara e única. O trabalho de Borges e Souza (2011) buscou mapear os métodos empregados para coleta, análise e interpretação de dados de pesquisas que as autoras classificaram como etnometodológicas, e no qual encontraram essa diversidade, sendo a maior parte dos estudos calcados na etnografia e analisados por meio da análise da conversação. Esta, apesar de comungar com pressupostos da etnometodologia, trata-se de uma derivação dela iniciada na década de 1960 por Schegloff e Sacks (Heritage, 1987). Bispo e Godoy (2011) utilizaram as práticas oriundas de um conjunto de atividades cotidianas como forma de analisar e interpretar os resultados sobre o uso da tecnologia em agências de viagens. Já Oliveira e Montenegro (2012), em uma versão mais apurada do artigo publicado por Oliveira et al. (2010), sugerem a aproximação do sensemaking de Karl Weick com a etnometodologia) para realização do processo de análise e interpretação de dados.

\section{Considerações Finais: Refletindo sobre Aprendizagem nas Organizações, o Conceito de Prática e a Etnometodologia}

A literatura sobre etnometodologia é relativamente vasta, entretanto, no campo da Administração e, em especial, no contexto brasileiro, são poucas as publicações. Tal fato faz com que exista uma lacuna de estudos empíricos etnometodológicos, assim como referências sobre como realizar metodologicamente e tecnicamente esse tipo de pesquisa (Oliveira et al., 2010; Oliveira \& Montenegro, 2012).

Oliveira et al. (2010, p. 15) defendem a etnometodologia nos estudos organizacionais em razão da discussão da natureza das organizações enquanto "produtos de uma realidade socialmente construída a partir das interações dos sujeitos e pautada em um contexto intersubjetivo de compartilhamento de significados" retomando-se "a ideia de que as organizações são constituídas por pessoas em suas práticas cotidianas e só existem a partir delas em um processo constante de construção e reconstrução".

Nesse sentido, a utilização da etnometodologia na investigação da aprendizagem nas organizações coloca-se como uma tarefa que ainda está por ser realizada na realidade brasileira, e implica em realizar pesquisas em que o foco esteja em compreender os processos de aprendizagem como construção coletiva que se dá por meio de interações sociais, intersubjetividade e criação de sentido no cotidiano. Dessa forma, é esperada como resultado a identificação de práticas que são constituídas e modificadas coletivamente de forma tácita, situada e natural. O processo de aprendizagem está na busca da condição que Garfinkel (2006) chama de unique adequacy, ou seja, como as pessoas adquirem a condição de membro em um grupo de trabalho (prática), considerando tanto os aspectos técnicos quanto os comportamentais. 
Pensar as organizações como espaços de construção coletiva de sentidos, significados e geração de conhecimento, em especial, o conhecimento tácito, implica também em buscar novas maneiras de compreender os processos de aprendizagem de natureza informal e que fazem parte do cotidiano das pessoas, dos grupos de trabalho e das organizações. Nesse sentido, é preciso buscar meios de acessar como a aprendizagem se dá enquanto condição de grupo e de forma naturalística, ou seja, na vida cotidiana do trabalho como discutem os trabalhos de Gherardi, Nicolini e Odella (1998), Strati (2003), Cook e Yanow (1993), Bruni (2005), Bruni, Gherardi e Parolin (2007), Nicolini (2010a, 2010b).

Partindo destas considerações, parece que a adoção de um arcabouço teórico que esteja alinhado epistemológica e metodologicamente com a geração de conhecimento no cotidiano, tomando como base a construção do senso comum, como proposto pela etnometodologia, pode contribuir para o avanço dos EBP e da compreensão dos processos de aprendizagem nas organizações.

O conceito de prática parece contribuir no sentido de chamar a atenção para a necessidade de entender o cotidiano organizacional em seu processo de organizing e knowing-in-practice, ou seja, perceber que as práticas representam o aprendizado coletivo em que o conhecimento não está na mente das pessoas como um processo apenas cognitivo, mas socialmente construído por meio das interações e da linguagem (Gherardi, 2006).

Assim, trazer o conceito de prática como uma forma de pesquisar e compreender os processos de aprendizagem nas organizações vem ao encontro da possibilidade de existirem organizações mais versáteis e dinâmicas em ambientes de incerteza e volatilidade que exigem respostas cada vez mais rápidas às demandas que surgem. Entretanto, não basta apenas estabelecer um debate raso sobre como as organizações geram conhecimento e inovação a partir de um olhar para as interações e o cotidiano. Nesse sentido, a utilização da etnometodologia como abordagem teórico-metodológica contribui também para que haja uma profundidade no entendimento da atribuição de significado e da criação de sentido dentro das organizações, e de que maneira esses elementos estão relacionados e contribuem para os processos de aprendizagem.

É possível corroborar com o exposto por meio das palavras de Gherardi (2009b, p. 536)

Práticas não são apenas padrões recorrentes de ação (nível de produção), mas padrões de ações socialmente sustentadas (produção e reprodução). O que as pessoas produzem em suas práticas situadas não é apenas trabalho, mas também a (re)produção da sociedade. Neste sentido, prática é um conceito analítico que possibilita interpretação de como as pessoas alcançam ativamente ser-no-mundo. Uma prática não é reconhecida fora de seu significado criado intersubjetivamente e o que possibilita a reprodução competente de uma prática, repetidas vezes e, o seu refinamento enquanto praticada (ou o seu abandono) é a constante negociação do que se pensa ser um modo correto ou incorreto de praticar dentro da comunidade de seus praticantes.

Um desdobramento do significado das práticas é a questão de que o conhecimento não é algo que as pessoas têm, ou estocam em suas mentes, mas que esse repertório é o resultado de uma série de processos coletivos que possibilitam o seu surgimento, compartilhamento e perpetuidade. É por este argumento que Gherardi (2009b) aponta que as práticas são formas de produção e reprodução social, destacando, ainda, o fato de que as pessoas buscam sua condição de ser-no-mundo e não apenas de nele estar.

Acredita-se também que os EBP contribuem na compreensão dos processos de aprendizagem por possibilitarem uma posição crítica em relação ao entendimento de que a aprendizagem, assim como o conhecimento, é o resultado de decisões meramente racionais. Essa abordagem indica que esses processos estão em contínuo desenvolvimento, reprodução e mudança, baseados em entendimentos tacitamente compartilhados pela comunidade. Dessa maneira, as práticas facilitam acessar e interpretar o caráter tácito da grande parte não reflexiva do processo que não se consegue expressar por meio de palavras (Geiger, 2009).

Este ensaio buscou analisar a possibilidade de investigação dos processos de aprendizagem nas organizações a partir do conceito de prática e à luz da etnometodologia, examinando como se 
articulam tais ideias e em que medida elas trazem novas maneiras de ver e compreender esse fenômeno. A partir desse objetivo, acredita-se que exista uma dupla lacuna que pode ser preenchida a partir dessa proposta: a primeira delas refere-se à necessidade de opções teóricas para a discussão da aprendizagem no âmbito coletivo (grupal) nas organizações; e a segunda, à escassez de pesquisas e literatura disponível sobre etnometodologia, em especial, na Administração e no contexto brasileiro.

O desafio está colocado, embora se tenha que vencer, ainda, algumas dificuldades e limitações. Algumas dessas dificuldades podem ser encontradas nas críticas enfrentadas pela etnometodologia enquanto proposta teórico-metodológica como, por exemplo, as apontadas por Heritage (1987) quanto à falta de uma apresentação metodológica sistematicamente articulada, e Coser (1975), de que se trata de um método sem substância em uma espécie de sociologia de vale tudo, e, ainda, por Sharrock e Randall (2004), quanto à reprodutibilidade e à generalização dos dados das pesquisas etnometodológicas.

Por outro lado, em resposta às críticas endereçadas ao trabalho de Garfinkel, Zimmerman (1976) diz que, assim como qualquer outro movimento intelectual, a etnometodologia também nasceu na osbcuridade e, com o passar do tempo, é conhecida por um público mais amplo. A fala do autor traz de forma subjacente que os críticos da etnometodologia não entendiam a sua essência e, de certa maneira, não aceitam que a sociologia deveria repensar o seu mainstream que, segundo ele, vivia em crise nos anos 1960. Corroborando com Zimmerman (1976), mas trazendo a discussão para o campo da Administração em um contexto atual, Oliveira e Montenegro (2012) defendem que a etnometodologia traz contribuições para os estudos organizacionais no sentido de que, por meio das práticas sociais, é possível avançar na compreensão dos fenômenos organizacionais.

A defesa que o fenômeno da aprendizagem no âmbito das organizações, em especial a aprendizagem coletiva e organizacional, seja compreendido pelas lentes das práticas sociais a partir de uma postura etnometodológica de investigação teórico-empírica, dá-se em razão da necessidade latente de ampliar a construção do processo científico em torno dos elementos tácitos e estéticos que fazem parte do contexto organizacional e, por vezes, são desconsiderados por métodos que valorizam apenas a objetividade na investigação dos fenômenos, ou ainda explicam a aprendizagem organizacional fazendo uma extrapolação do que seria a aprendizagem individual cognitiva para o contexto das organizações, afirmando que estas aprendem com os indivíduos, evidenciando um viés de antropomorfização desse fenômeno nas organizações.

Além da aprendizagem organizacional, é possível citar que a etnometodologia pode contribuir no avanço das pesquisas da perspectiva da estratégia como prática no sentido de ampliar o entendimento de como emergem as estratégias nas organizações, na área de tecnologia da informação no que tange a compreensão do uso da tecnologia como prática e seus impactos nas organizações, entre outras áreas da Administração e afins a ela.

A adoção da etnometodologia como estratégia de investigação empírica sobre aprendizagem e outros fenômenos nas organizações não possui uma sistematização definida tanto na literatura internacional como na brasileira. No contexto nacional, autores estão adotando caminhos diversos para, especialmente, analisar e interpretar os dados da pesquisa de campo. Gondim (2008), ao investigar o desenvolvimento local de uma comunidade no Ceará, utilizou a fotoetnografia; Bispo e Godoy (2011) adotaram as próprias práticas como forma de categorizar os fenômenos encontrados em agências de viagem. Além destes estudos empíricos, Borges e Souza (2011) sugerem a utilização da análise da conversação e Oliveira e Montenegro (2012), um caminho baseado no sensemaking nos seus ensaios teóricos.

Apesar de ter sido identificado um arcabouço teórico comum utilizado por esses autores que convergem no entendimento de que fazer uma pesquisa etnometodológica é a busca da prática cotidiana dos membros de um grupo de forma naturalística e situada que por meio da intersubjetividade dão identidade a ele, por outro lado, os caminhos adotados para a condução da pesquisa e especialmente a sua forma de análise dos dados apresenta uma falta de unidade. É preciso ressaltar, como afirmam Ten Have (2004), Francis e Hester (2004) e Rawls (2008), que esta 
diversidade faz parte do fazer etnometodológico, entretanto, também é preciso reconhecer que há a necessidade do desenvolvimento de grupos de pesquisas que possam, ao menos, endereçar diretrizes que facilitem a adoção em maior escala da etnometodologia nos estudos sobre aprendizagem, assim como nos demais fenômenos organizacionais.

\section{Artigo recebido em 10.11.2011. Aprovado em 17.06.2012.}

\section{Notas}

\footnotetext{
${ }^{1}$ Para melhor compreensão do conceito de estética, ver Strati (2007).

2 Uma versão inicial deste trabalho foi apresentada no XIII SEMEAD (2010), sendo profundamente modificada, especialmente, em função das contribuições dos pareceristas que colaboraram conosco nas várias etapas de avaliação deste estudo.
}

\section{Referências}

Antonello, C. S., \& Godoy, A. S. (2009). Uma agenda brasileira para os estudos em aprendizagem organizacional. Revista de Administração de Empresas, 49(3), 266-281. doi: 10.1590/S003475902009000300003

Antonello, C. S., \& Godoy, A. S. (2010). A encruzilhada da aprendizagem organizacional: uma visão paradigmática. Revista de Administração Contemporânea, 14(2), 310-332. doi: 10.1590/S141565552010000200008

Bapuji, H., Crossan, M., \& Rouse, M. J. (2005, June). Organizational learning. Methodological and measurement issues. Proceedings of the International Conference on Organizational Learning and Knowledge, University of Trento, Italy, 6.

Bispo, M. S., \& Godoy, A. S. (2011, setembro). Compreendendo o processo de aprendizagem coletiva do uso de tecnologia como prática em agências de viagens: uma proposta etnometodológica. Anais do Encontro Nacional da Associação Nacional de Pós-Graduação e Pesquisa em Administração, Rio de Janeiro, RJ, Brasil, 35.

Borges, M. L. de, \& Souza, Y. S. de (2011, setembro). Contribuições da etnometodologia aos estudos organizacionais: a natureza extraordinária do trabalho ordinário. Anais do Encontro Nacional da Associação Nacional de Pós-Graduação e Pesquisa em Administração, Rio de Janeiro, RJ, Brasil, 35.

Bruni, A. (2005). Shadowing software and clinical records: on the ethnography of non-humans and heterogeneous contexts. Organization, 12(3), 357-378. doi: 10.1177/1350508405051272

Bruni, A., Gherardi, S., \& Parolin, L. L. (2007). Knowing in a system of fragmented knowledge. Mind, Culture, and Activity, 14(1-2), 83-102. doi: 10.1080/10749030701307754

Collins, R. (1994). Four sociological traditions. New York: Oxford University Press.

Conlon, T. J. (2004). A review of informal learning literature, theory and implications for practice in developing global professional competence. Journal of European Industrial, Training, 28(2-34), 283-295. doi: 10.1108/03090590410527663

Cook, S. D. N., \& Yanow, D. (1993). Culture and organizational learning. Journal of Management Inquiry, 2(4), 373-390. doi: 10.1177/105649269324010 
Coser, L. A. (1975). Presidential address: two methods in search of a substance. American Sociological Review, 40(6), 691-700. doi: 10.2307/2094174

Coulon, A. (2005). La etnomedotología (3a ed.). Madrid: Cátedra.

Easterby-Smith, M. (1997). Disciplines of organizational learning: contributions and critiques. Human Relations, 50(9), 1085-1113. doi: 10.1177/001872679705000903

Easterby-Smith, M., Crossan, M., \& Nicolini, D. (2000). Organizational learning: debates past, present and future. Journal of Management Studies, 37(6), 783-796. doi: 10.1111/1467-6486.00203

Easterby-Smith, M., \& Lyles, M. (2003). Watersheds of organizational learning and knowledge management. In M. Easterby-Smith \& M. A. Lyles (Orgs.), The Blackwell handbook of organizational learning and knowledge management (pp. 1-15). Oxford: UK: Blackwell Publishing.

Elkjaer, B. (2003). Social learning theory: learning as participation in social process. In M. EasterbySmith \& M. A. Lyles (Orgs.), The Blackwell handbook of organizational learning and knowledge management (pp. 38-53) Oxford: UK: Blackwell Publishing.

Elkjaer, B. (2004). Organizational learning: the 'third way'. Management Learning, 35(4), 419-434. doi: $10.1177 / 1350507604048271$

Francis, D., \& Hester, S. (2004). An invitation to ethnomethodology: language, society and interaction. London: Sage.

Garfinkel, H. (2006). Studios en etnometodología. Barcelona: Anthropos.

Geiger, D. (2009). Revisiting the concept of practice: toward an argumentative understanding of practicing. Management Learning, 40(2), 129-144. doi: 10.1177/1350507608101228

Gherardi, S. (2000). Practice-based theorizing on learning and knowing in organizations. Organization, 7(2), 211-223. doi: 10.1177/135050840072001

Gherardi, S. (2001). From organizational learning to practice-based knowing. Human Relations, 54(1), 131-139. doi: 10.1177/0018726701541016

Gherardi, S. (2006). Organizational knowledge: the texture of workplace learning. Oxford: Blackwell Publishing.

Gherardi, S. (2009a). Introduction: the critical power of the 'practice lens'. Management Learning, 40(2), 115-128. doi: 10.1177/1350507608101225

Gherardi, S. (2009b). Practice? It's a matter of taste! Management Learning, 40(5), 535-550. doi: $10.1177 / 1350507609340812$

Gherardi, S., \& Nicolini, D. (2001). The sociological foundations of organizational learning. In M. Dierkes, A. Berthoin Antal, J. Child, \& I. Nonaka (Orgs.), The handbook of organizational learning and knowledge (pp. 35-60). Oxford: Oxford University Press.

Gherardi, S., Nicolini, D., \& Odella, F. (1998). Toward a social understanding of how people learn in organizations: the notion of situated curriculum. Management Learning, 29(3), 273-297. doi: $10.1177 / 1350507698293002$

Gondim, R. V. (2008, maio) As contribuições da etnometodologia e da fotoetnografia nas reflexões empíricas e imagéticas do desenvolvimento local da prainha do Canto Verde. Anais do Encontro de Estudos Organizacionais da ANPAD, Porto Alegre, RS, Brasil, 7. 
Hatch, M. J., \& Yanow, D. (2003). Organization theory as an interpretative science. In H. Tsoukas \& C. Knudsen (Orgs.), The oxford handbook of organization theory (pp. 63-87). Oxford: Oxford University Press.

Heritage, J. C. (1987). Ethnomethodology. In A. Giddens \& J. Turner (Eds.), Social theory today (pp. 224-272). Cambridge: Polity Press.

Marcon, T., \& Gopal, A. (2008). Irony, critique and ethnomethodology in the study of computer work: irreconcilable tensions? Information Systems Journal, 18(2), 165-184. doi: 10.1111/j.13652575.2007.00285.x

Marsick, V. J. (2009). Toward a unifying framework to support informal learning theory, research and practice. Journal of Workplace Learning, 21(4), 265-275. doi: 10.1108/13665620910954184

Marsick, V. J., \& Watkins, K. E. (2001). Informal and incidental learning. New Directions for Adult and Continuing Education, (89), 25-34.

Maynard, D. W., \& Clayman, S. E. (1991). The diversity of ethnomethodology. Annual Review of Sociology, 17(1), 385-418. doi: 10.1146/annurev.so.17.080191.002125

Nicolini, D. (2009). Articulating practice through the interview to the double. Management Learning, 40(2), 195-212. doi: 10.1177/1350507608101230

Nicolini, D. (2010a). Medical innovation as a process of translation: a case from the field of telemedicine. British Journal of Management, 21(4), 1011-1026.

Nicolini, D. (2010b). Practice as the site of knowing: insights from the field of telemedicine. Organization Science. Recuperado de http://orgsci.journal.informs.org/content/22/3/602. doi: 10.1287/orsc.1100.0556

Nicolini, D., Gherardi, S., \& Yanow, D. (2003). Introduction: toward a practice-based viewof knowing and learning in organizations. In D. Nicolini, S. Gherardi, \& D. Yanow (Orgs.), Knowing in organizations: a practice-based approach (pp. 3-31). London: Sharpe.

Oliveira, S. A. de, \& Montenegro, L. M. (2012). Etnometodologia: desvelando a alquimia da vivência cotidiana. Cadernos EBAPE.BR, 10(1), 129-145. doi: 10.1590/S1679-39512012000100009

Oliveira, S. A. de, Montenegro, L. M., Machado-da-Silva, C. L., \& Rese, N. (2010, maio). Etnometodologia: desvelando a alquimia da vivência cotidiana. Anais do Encontro da Divisão de Estudos Organizacionais da ANPAD, Florianópolis, SC, Brasil, 6.

Pollner, M., \& Emerson, R. M. (2001). Ethnomethodology and ethnography. In P. Atkinson, A. Coffey, S. Delmont, J. Lofland, \& L. Lofland (Eds.), Handbook of ethnography (pp. 118-135). London: Sage.

Psathas, G. (2004). Alfred Schutz's influence on American sociologists and sociology. Humam Studies, 27(1), 1-35. doi: 10.1023/B:HUMA.0000012249.47522.56

Rawls, A. W. (2002). Editor's introduction. In A. W. Rawls (Ed.), Ethnomethodology's program: working out Durkheim's aphorism (pp. 1-64). Massachusetts, USA: Rowman \& Littlefield Publishers Inc., Lantham.

Rawls, A. W. (2008). Harold Garfinkel, ethnomethodology and workplace studies. Organization Studies, 29(5), 701-732. doi: 10.1177/0170840608088768

Romero, J. J. C. (1991). Etnometodologia: una explicación de la construcción social de la realidad. Revista Española de Investigaciones Sociológicas, 56, 83-114. 
Sharrock, W., \& Randall, D. (2004). Ethnography, ethnomethodology and the problem of generalization in design. European Journal of Information Systems, 13(3), 186-194. doi: 10.1057/palgrave.ejis.3000502

Shipton, H. (2006). Cohesion or confusion? Towards a typology for organizational learning research. International Journal of Management Reviews, 8(4), 233-252. doi: 10.1111/j.14682370.2006.00129.x

Strati, A. (2003). Knowing in practice: a esthetic understanding and tacit knowledge. In D. Nicolini, S. Gherardi, \& D. Yanow (Eds.), Knowing in organizations: a practice-based approach (pp. 5375). New York: M.E. Sharpe.

Strati, A. (2007). Sensible knowledge and practice-based learning. Management Learning, 38(1), 6177. doi: $10.1177 / 1350507607073023$

Strati, A. (2009). Do you do beautiful things? A esthetics and art in qualitative methods of organization studies. In D. Buchanan \& A. Bryman (Eds.), The sage handbook of organizational research methods (pp. 230-245). London: Sage.

Suchman, L. (2003). Organizing alignment: the case of bridge-building. In D. Nicolini, S. Gherardi, \& D. Yanow (Orgs.), Knowing in organizations: a practice-based approach (pp. 187-203). New York: M. E. Sharpe.

Ten Have, P. (2004). Understanding qualitative research and ethnomethodology. London: Sage.

Tsoukas, H. (2003). Do we really understand tacit knowledge? In M. Easterby-Smith \& M. Lyles (Orgs.), The Blackwell handbook of organizational learning and knowledge management (pp. 410-427). Oxford: Blackwell Publishing.

Vera, D. (2009). On building bridges, facilitating dialogue, and delineating priorities: a tribute to Mark Easterby-Smith and his contribution to organizational learning. Management Learning, 40(5), 499-511. doi: 10.1177/1350507609341696

Wenger, E. (2000). Communities of practice and social learning systems. Organization, 7(2), 225-246. doi: $10.1177 / 135050840072002$

Zimmerman, D. H. (1976). A reply to professor Coser. The American Sociologist, 11(1), 4-13. 